\title{
Current therapy of granulomatosis with polyangiitis and microscopic polyangiitis: the role of rituximab
}

\author{
Duvuru Geetha $\cdot$ Cees Kallenberg $\cdot$ John H. Stone $\cdot$ \\ Alan D. Salama • Gerald B. Appel • \\ George Duna $\cdot$ Paul Brunetta $\cdot$ David Jayne
}

Received: 1 May 2014/ Accepted: 26 August 2014/Published online: 4 September 2014

(C) Italian Society of Nephrology 2014

\begin{abstract}
Granulomatosis with polyangiitis and microscopic polyangiitis are anti-neutrophil cytoplasmic antibody-associated vasculitides (AAVs) that are prone to cycles of remission and relapse. The introduction of cytotoxic therapy has changed the prognosis for these diseases from typically fatal to manageable chronic illnesses with a relapsing course. Despite improvements in outcomes, recurrence of disease and drug-related toxicity continue to produce significant morbidity and mortality. Better understanding of the pathogenesis of AAV and the mechanism of
\end{abstract}

\section{Geetha $(\square)$}

Division of Nephrology, Johns Hopkins University School of Medicine, Johns Hopkins Bayview Medical Center, 301 Mason Lord Drive, Suite 2500, Baltimore, MD, USA

e-mail: gduvura@jhmi.edu

C. Kallenberg

Department of Rheumatology and Clinical Immunology, University of Groningen, University Medical Center Groningen, Groningen, The Netherlands

\section{J. H. Stone}

Division of Rheumatology, Department of Medicine, Massachusetts General Hospital, Boston, MA, USA

A. D. Salama

Centre for Nephrology, UCL, London, UK

G. B. Appel

Columbia University College of Physicians and Surgeons,

The Glomerular Kidney Disease Center, New York, NY, USA

G. Duna $\cdot$ P. Brunetta

Genentech, Inc., South San Francisco, CA, USA

D. Jayne

Vasculitis and Lupus Clinic, Addenbrooke's Hospital,

Cambridge, UK action of cyclophosphamide has led to investigation of therapies that target B cells. Two randomized controlled trials have shown that rituximab is not inferior to cyclophosphamide for induction of remission in severe AAV, with no significant difference in the incidence of overall adverse events in rituximab- versus cyclophosphamidetreated patients. Data from ongoing clinical trials will determine the role of rituximab in the maintenance of remission.

Keywords Anti-neutrophil cytoplasmic antibody . Renal · Rituximab · Vasculitis

\section{Introduction}

Granulomatosis with polyangiitis (GPA) and microscopic polyangiitis (MPA) are rare small-vessel vasculitides that are characterized by the presence of circulating anti-neutrophil cytoplasmic autoantibodies (ANCAs) in 80-94\% of affected patients [1, 2]. The prevalence of ANCAassociated vasculitis (AAV) has increased in recent years, in part due to increased recognition of these complex diseases. AAVs have an annual incidence of 20 per million population [3]. Renal involvement is present in $>50 \%$ of patients at presentation and develops in 70-80\% during the course of the disease. The typical histopathology is a focal segmental and necrotizing crescentic glomerulonephritis (GN) with minimal immunoglobulin deposition in vessel walls [4]. GPA and MPA account for $80 \%$ of cases of rapidly progressive GN [5]. Progression to end-stage renal disease (ESRD) can be prevented by prompt diagnosis and timely initiation of therapy.

GPA and MPA are severe, progressive diseases that, left untreated, can lead to death from multisystem organ 
failure. The introduction of therapy with glucocorticoids combined with cyclophosphamide improved the prognosis for AAV [6]. However, not all patients respond to cyclophosphamide, and $>50 \%$ of responders suffer a relapse within 3-5 years [7]. Disease recurrence and drug-related toxicity continue to produce significant morbidity and mortality, and remain the main challenges in patient management [8]. In a recent analysis of four European clinical trials involving 524 AAV patients, the greatest impact on patients in the first year of therapy was from adverse events (AEs) rather than active vasculitis [9]. In this analysis, the burden of AEs was quantified using a severity score for leukopenia, infection, and other AEs with additional weighting for follow-up duration. The burden of AEs was predicted by the severity of renal impairment and advanced age.

ANCAs are implicated in the pathogenesis of GPA and MPA [10]. Consequently, therapies targeting the cells that produce these antibodies (short-lived plasma cells of B-cell origin) and other functions of B cells, such as antigen presentation and cytokine release, have been considered as potential treatments for AAV. After promising initial data from smaller studies, two randomized clinical trials have shown that rituximab, an anti-CD20 monoclonal antibody that targets B cells, is not inferior to cyclophosphamide for induction of remission in severe GPA and MPA [11, 12]. Consequently, in April 2011 the US FDA approved rituximab for the treatment of these diseases, heralding a new era in disease management. The aim of this review is to examine the latest evidence supporting the use of rituximab in GPA/MPA within the context of other available treatment approaches.

\section{Current treatment options}

The European Vasculitis Study Group (EUVAS) classifies AAV according to particular subtypes in order to assign different treatment regimens (Table 1) [13]. Therapy consists of a staged treatment approach involving two treatment phases: remission-induction and remissionmaintenance.

\section{Standard of care}

Combination therapy with corticosteroids and cyclophosphamide was established as standard therapy after the seminal paper published by Fauci et al. [6]. Prolonged courses of cyclophosphamide are effective for the treatment of AAV, with $91 \%$ of patients showing improvement in disease status and $75 \%$ achieving sustained disease remission. However, the cost of achieving remission using this extended cyclophosphamide dosing regimen was substantial: $46 \%$ of patients developed a serious infection, $57 \%$ became infertile, and $43 \%$ developed hemorrhagic cystitis. In addition, there was a 33 -fold increased risk of bladder carcinoma and an 11-fold increased risk of lymphoma. Overall, $42 \%$ of patients developed some form of serious morbidity directly attributable to therapy when cyclophosphamide was used for 2 years according to the $\mathrm{NIH}$ regimen. Modern treatment strategies have focused on minimizing cyclophosphamide exposure or eliminating its use altogether. Pulsed cyclophosphamide administration has been considered as a less toxic alternative to daily cyclophosphamide $[14,15]$. Both pulsed cyclophosphamide [15 mg/kg intravenously (IV) every $2-3$ weeks] and

Table 1 EUVAS disease categorization for GPA/MPA and treatment recommendations for induction and maintenance of remission [13]

\begin{tabular}{|c|c|c|c|}
\hline $\begin{array}{l}\text { EUVAS } \\
\text { disease } \\
\text { subtype }\end{array}$ & Definition & Induction & Maintenance \\
\hline Localized & $\begin{array}{l}\text { Upper and/or lower respiratory tract } \\
\text { disease without other systemic } \\
\text { involvement or constitutional symptoms }\end{array}$ & Methotrexate + steroids & $\begin{array}{l}\text { Low-dose } \\
\text { steroids }+ \text { azathioprine } \\
\text { or methotrexate }\end{array}$ \\
\hline $\begin{array}{l}\text { Early } \\
\text { systemic }\end{array}$ & $\begin{array}{l}\text { Without organ-threatening or life- } \\
\text { threatening disease }\end{array}$ & Methotrexate or cyclophosphamide + steroids & $\begin{array}{l}\text { Low-dose } \\
\text { steroids }+ \text { azathioprine } \\
\text { or methotrexate }\end{array}$ \\
\hline Generalized & $\begin{array}{l}\text { Renal or other life-threatening disease; } \\
\text { serum creatinine }<500 \mu \mathrm{mol} / 1\end{array}$ & $\begin{array}{l}\text { Cyclophosphamide or rituximab }{ }^{\text {a }} \text { (or mycophenolate } \\
\text { mofetil) }+ \text { steroids }\end{array}$ & $\begin{array}{l}\text { Low-dose } \\
\text { steroids }+ \text { azathioprine }\end{array}$ \\
\hline Severe & $\begin{array}{l}\text { Renal or other vital organ failure; serum } \\
\text { creatinine }>500 \mu \mathrm{mol} / 1\end{array}$ & $\begin{array}{l}\text { Cyclophosphamide or rituximab }{ }^{\mathrm{a}}+\text { steroids }+ \text { plasma } \\
\text { exchange }\end{array}$ & $\begin{array}{l}\text { Low-dose } \\
\text { steroids }+ \text { azathioprine }\end{array}$ \\
\hline Refractory & $\begin{array}{l}\text { Progressive disease unresponsive to } \\
\text { cyclophosphamide and glucocorticoids }\end{array}$ & $\begin{array}{l}\text { Rituximab, mycophenolate mofetil, intravenous } \\
\text { immunoglobulin, anti-thymocyte globulin, } \\
\text { 15-deoxyspergualin, alemtuzumab, hematopoietic } \\
\text { stem cell transplantation }\end{array}$ & - \\
\hline
\end{tabular}

${ }^{a}$ Rituximab can be recommended for newly diagnosed, relapsing, and refractory disease 
daily cyclophosphamide $(2 \mathrm{mg} / \mathrm{kg} /$ day $)$ produce similar remission rates, although long-term follow-up of patients enrolled in the CYCLOPS trial indicates that the risk of relapse continues to increase among patients treated with pulsed cyclophosphamide [16]. Between 10 and $40 \%$ of patients fail to achieve sustained remission with standard induction therapy through inefficacy, severe AEs, or intolerance [14-16].

For remission-maintenance, the CYCAZAREM trial showed that cyclophosphamide could be replaced with azathioprine after remission without increasing the rate of relapse [17]. Azathioprine and low-dose steroid tapered to $\leq 10 \mathrm{mg} /$ day are recommended to reduce exposure to cyclophosphamide and steroids, although relapses occur in $>50 \%$ of patients by 7 years $[13,17,18]$. The IMPROVE trial tested the use of mycophenolate mofetil (MMF) as a remission-maintenance agent in 156 patients with AAV [19]. The rate of relapse with MMF 2,000 mg daily with dose further reduced at 12 months to $1,500 \mathrm{mg}$ daily and at 18 months to $1,000 \mathrm{mg}$ daily was almost double that observed with azathioprine $2 \mathrm{mg} / \mathrm{kg} /$ day [adjusted hazard ratio for relapse associated with MMF, 1.80 (95 \% confidence interval 1.10-2.93); $P=0.02$ ], indicating that MMF at the dose used is not as effective as azathioprine for maintaining disease remission. Methotrexate is another alternative as a remission-maintenance agent [20].

\section{Alternatives to standard of care}

Standard of care for remission-induction may not be sufficient or appropriate for all patients with GPA/MPA. Methotrexate can be used as an alternative to cyclophosphamide in patients without renal involvement or with only mild renal involvement (early systemic disease) [21]. Long-term observation, however, shows that induction treatment with methotrexate results in less effective disease control than cyclophosphamide-based induction therapy [22]. MMF is an alternative to cyclophosphamide for remission-induction in patients with mild to moderate renal disease [23]. A randomized, non-inferiority trial (MYCYC) compared remission-induction with MMF or cyclophosphamide in newly diagnosed GPA/MPA. The study did not reach its primary endpoint of demonstrating that MMF is non-inferior to cyclophosphamide in terms of remissioninduction when steroids were used according to protocol, although non-inferiority was shown for remission-induction irrespective of steroid compliance [24].

For patients with severe (life-threatening) AAV, adjunctive plasma exchange may be considered. MEPEX was a randomized, controlled trial comparing IV methylprednisolone or plasma exchange with cyclophosphamide and oral prednisolone in severe renal vasculitis, with renal recovery as the primary outcome measure [25]. At
3 months, a significantly greater proportion of patients who received plasma exchange were alive and independent of dialysis compared with those who received IV methylprednisolone (69 versus $49 \%, P=0.02$ ), thus supporting the use of plasma exchange in the treatment of AAV with renal failure. The use of adjunctive plasma exchange with standard immunosuppressive therapy and glucocorticoids in less severe renal disease is being investigated in PEXIVAS, a large international multicenter trial.

\section{Rituximab}

\section{Rationale for B-cell-targeted therapy}

Rituximab was first FDA approved in 1997 for the treatment of non-Hodgkin lymphoma. It is also licensed in rheumatoid arthritis (RA) for treating patients with an inadequate response to tumor necrosis factor- $\alpha$ inhibitors. Rituximab has also been studied in patients with glomerular diseases, including lupus nephritis, membranous nephropathy, and focal glomerulosclerosis [26-29]. The rationale for using rituximab in GPA/MPA stems from the central role played by B cells in the pathogenesis of these diseases and evidence for the pathogenicity of circulating ANCAs [30]. B cells are the precursors of short-lived plasma cells, which are thought to be the primary source of autoantibodies, including ANCAs. B cells may contribute to other aspects of the pathogenesis of GPA and MPA, including co-stimulation, cytokine production, and antigen presentation [30]. The action of cyclophosphamide also points to a role for B cells, as it may exert some of its activity in GPA/MPA through the suppression of B-cell function [31].

\section{Rituximab for remission-induction in GPA/MPA}

Patients with GPA/MPA have experienced remission rates of approximately $90 \%$ with rituximab in open-label clinical trials and case series [32-34]. However, these studies were neither randomized nor controlled, and criteria for remission were not rigidly applied. Two recent randomized controlled trials (RAVE and RITUXVAS) investigated the efficacy and safety of rituximab in GPA/MPA. The US FDA approval of rituximab was based on data from the RAVE study [11]. RAVE enrolled 197 patients with severe GPA/MPA, approximately $50 \%$ of whom had newly diagnosed disease and $50 \%$ had severe relapsing disease at diagnosis. Patients with severe renal impairment (serum creatinine $>4 \mathrm{mg} / \mathrm{dl}$ ) and those requiring intubation for alveolar hemorrhage were excluded. However, $66 \%$ of each group had renal disease at baseline, and lung involvement was present in a little over half of each group 
with pulmonary hemorrhage in approximately one quarter of each group.

This was a double-blind, double-dummy, controlled, randomized trial with preset primary, secondary, and tertiary endpoints. Patients were randomized to receive either rituximab $\left(375 \mathrm{mg} / \mathrm{m}^{2}\right.$ once weekly for 4 weeks) or oral cyclophosphamide ( $2 \mathrm{mg} / \mathrm{kg} /$ day) for a maximum of 6 months (remission-induction period). All patients received the same glucocorticoid regimen (1-3 pulses of IV methylprednisolone $1,000 \mathrm{mg}$, followed by oral prednisone $1 \mathrm{mg} / \mathrm{kg}$ tapered over 5 months). On achieving remission at 3-6 months, patients in the cyclophosphamide arm were switched to a remission-maintenance regimen of azathioprine $2 \mathrm{mg} / \mathrm{kg} /$ day. Patients in the rituximab group who achieved remission during the same period were maintained on placebo rather than azathioprine after initial rituximab except for a tapering corticosteroid dose similar to the cyclophosphamide group, They thus received no active treatment after 5 months, when their prednisone was discontinued. Patients were followed for at least 18 months to gauge long-term responses and the effect of rituximab on immune tolerance. The primary endpoint was achievement of complete remission, as defined by a Birmingham Vasculitis Activity Score for Wegener's Granulomatosis (BVAS/WG) [35] of zero and no prednisone by 6 months.

At 6 months, $64 \%$ of rituximab-treated patients achieved the primary endpoint versus $53 \%$ in the cyclo- by $71 \%$ of rituximab- and $62 \%$ of cyclophosphamidetreated patients. Results from the long-term follow-up of the RAVE trial showed 48 and $39 \%$ of patients in the rituximab arm were in sustained remission at 12 and 18 months compared to 39 and $33 \%$ of patients in the CYC arm, demonstrating that remission-induction with rituximab without any maintenance therapy was non-inferior to CYC followed by azathioprine [36].

Approximately half of the patients in RAVE had major renal disease at baseline (Box 1). Although baseline mean estimated glomerular filtration rate (e-GFR) was significantly worse in the rituximab group (creatinine clearance 53 versus $69 \mathrm{ml} / \mathrm{min}$; $P=0.01$ ), the proportion of renal patients achieving the study primary endpoint was not significantly different between the two groups (rituximab $61 \%$ versus cyclophosphamide $63 \% ; P=0.92$ ) [37]. There was no difference in the proportion of patients with sustained remission at 18 months (rituximab $42 \%$ versus cyclophosphamide $43 \% ; P=0.84$ ). Mean e-GFR also increased in parallel in both groups. There was no overall difference in the incidence of renal flares between groups; however, MPA patients treated with rituximab were more likely to experience renal flares than those treated with cyclophosphamide/azathioprine (4 MPA patients treated with rituximab had a total of 5 renal flares by month 18 versus none treated with cyclophosphamide/azathioprine; $P=0.04)$.

Box 1: Definition of major renal disease in the RAVE study [11]

$\geq 1$ major renal BVAS/WG item, which includes new or worsening events of the following two

symptoms:

- Red blood cell casts;

- A rise in creatinine $>30 \%$ or a fall in creatinine clearance $>25 \%$;

and/or

- Biopsy proven pauci-immune glomerulonephritis.

phosphamide group, a result that met the criterion for noninferiority $(P<0.001)$. In patients with relapsing disease at baseline, $67 \%(34 / 51)$ of patients in the rituximab group and $42 \%(21 / 50)$ of patients in the cyclophosphamide group achieved complete remission $(P=0.01)$. A secondary endpoint was remission defined as BVAS/WG of 0 and prednisone $\leq 10 \mathrm{mg} /$ day; this endpoint was achieved
The safety data from RAVE showed no significant differences between the treatment groups in the incidence of AEs, serious AEs, or non-disease-related AEs [11]. There were more infusion reactions with rituximab (but only during the initial infusion-12 vs. $7 \%$ ) and serious infections (sepsis and pneumonia) were found in about $10 \%$ of either group. Two patients in each treatment group 
died. No additional safety issues were detected in patients followed for $\geq 18$ months [38], including no difference in new malignancies between the groups ( 6 and 2 cases in the rituximab and cyclophosphamide groups, respectively; further details are available in Stone et al. [11]).

RITUXVAS was a multicenter open-label study that recruited patients with newly diagnosed AAV and renal involvement (severe GPA/MPA) [12]. Patients enrolled in RITUXVAS were older (median age 68 years) than the patients in the RAVE cohort (mean age 51-54 years) and had worse renal function at baseline (median GFR $12-20 \mathrm{ml} / \mathrm{min}$ in RITUXVAS and mean GFR 54-69 $\mathrm{ml} /$ min in RAVE). Study participants were randomized to treatment with rituximab $\left(375 \mathrm{mg} / \mathrm{m}^{2}\right.$ once weekly for 4 weeks) plus two IV cyclophosphamide pulses, or IV cyclophosphamide for 3-6 months (control group). For remission-maintenance, the control group received oral azathioprine for up to 12 months. This trial included patients who had severe renal disease, with 9/44 patients requiring dialysis at trial entry. All patients received the same glucocorticoid regimen of IV methylprednisolone $1,000 \mathrm{mg}$, followed by oral prednisolone $1 \mathrm{mg} / \mathrm{kg} / \mathrm{day}$, tapered to $5 \mathrm{mg} /$ day by 6 months. Rates of sustained remission (over 12 months) were high in both treatment groups, although they did not differ significantly: rituximab/cyclophosphamide $76 \%$ (25/33) and cyclophosphamide $82 \%(9 / 11)(P=0.68)$. Mortality in this older, renal-impaired group was high $(18 \%)$ in both treatment groups, although the incidence of serious AEs and infections was similar in the two treatment groups.

\section{Rituximab for remission-induction in refractory GPA/ MPA}

EUVAS defines refractory disease as progressive disease unresponsive to cyclophosphamide and corticosteroids [13]. Among GPA/MPA patients receiving standard therapy of cyclophosphamide and glucocorticoids, up to $5 \%$ are refractory to treatment (see Table 1) [39]. The first use of rituximab to treat refractory vasculitis was described in 2001 [40]. Other groups have since shown that rituximab is effective at inducing remission in GPA/MPA patients with refractory disease [41-43]. In one multicenter series involving 65 patients with refractory disease, complete remission was achieved in $75 \%$ of patients treated with rituximab [44].

\section{Glucocorticoid taper}

As high-dose glucocorticoid treatment is associated with considerable toxicity, implementing measures to reduce glucocorticoid exposure without increasing the risk of relapse is critical. Current remission-induction regimens include high-dose glucocorticoids, which are then tapered when remission is achieved [13]. The relationship between glucocorticoid dose and its immunosuppressive and antiinflammatory actions is complex [45].

When combined with cytotoxic medications, high-dose glucocorticoids may increase treatment-related toxicity. Infections in GPA/MPA are most common in the first 2 months of treatment when glucocorticoid doses are highest. Although this relationship is confounded by disease activity and co-treatment with cytotoxic therapy, it is important to note that infection rates fall in parallel with decreasing glucocorticoid dose despite the maintenance of cytotoxic agents. Glucocorticoid dose-dependent increases in infections have been observed in RA [46]. Furthermore, high cumulative doses of glucocorticoids are associated with other comorbidities, including osteoporosis, cardiovascular disease, and gastrointestinal bleeding [47]. Despite the evidence for an association between higher glucocorticoid doses and AEs, there is a paucity of evidence to guide the optimal glucocorticoid dosing in GPA/ MPA.

Results from RAVE and RITUXVAS indicate that glucocorticoid tapering can be achieved during remissioninduction with either rituximab or cyclophosphamide. In RAVE, patients received 1-3 pulses of IV methylprednisolone $(1,000 \mathrm{mg}$ each), followed by oral prednisone $(1 \mathrm{mg} /$ $\mathrm{kg}$ /day) with dose tapering, such that by 5 months all patients in remission without disease flare had discontinued glucocorticoids completely [11]. The glucocorticoid taper occurred later in RITUXVAS: the prednisolone dose was $5 \mathrm{mg} /$ day at 6 months [12]. By 12 months, the median weightadjusted doses of prednisolone were still approximately $5 \mathrm{mg}$ daily $(0.071$ and $0.082 \mathrm{mg} / \mathrm{kg} /$ day $)$ in the rituximab and control groups, respectively. Another uncontrolled study in patients with renal AAV, involving induction therapy with low-dose cyclophosphamide plus rituximab followed by azathioprine maintenance, employed a low-dose glucocorticoid regimen with withdrawal at 3 months [48]. This strategy proved effective, with a relapse rate of only $13 \%$ over 18 months and an acceptable safety profile. The PEXIVAS trial is designed to determine the non-inferiority of a reduced-dose glucocorticoid regimen compared with standard-dose glucocorticoids in reducing death and ESRD.

If the decision is made to use a remission-maintenance regimen in AAV, low-dose glucocorticoids are often used in combination with azathioprine or methotrexate. The optimal dose and duration of glucocorticoid therapy in relapse prevention have not been established. The efficacy of long-term, low-dose glucocorticoids to prevent relapses is controversial and must be balanced with the risk of AEs due to toxicity from high cumulative doses of glucocorticoids. A systematic review and meta-analysis of 13 studies $(n=983)$ concluded that longer courses of glucocorticoids 
were associated with fewer relapses and that low-dose glucocorticoids for $>12$ months would be anticipated to provide benefits for patients [18]. In contrast, a cohort study that evaluated the effect of glucocorticoid therapy on patient outcomes and AEs reported that therapy beyond 6 months was associated with a significantly greater risk of infections but no significant reduction in the rate of relapse [49].

Rituximab as maintenance immunosuppressive therapy in GPA/MPA

GPA and MPA are relapsing diseases, with approximately $50 \%$ of patients following a chronic relapsing pattern, despite standard immunosuppression. Studies have shown that relapse may be more common in anti-proteinase 3 -positive patients $[50,51]$. The use of rituximab as maintenance therapy to prevent relapses in AAV has been evaluated in two open-label studies. In one study, 2-year fixed-interval re-treatment with rituximab was shown to lower relapse rate and maintain remission for a prolonged period compared with rituximab treatment at the time of flare [52]. Administration of rituximab preemptively on the basis of B-cell repletion has also been shown to be effective in preventing relapses [53]. Other open-label studies have confirmed the effectiveness of rituximab as a maintenance immunosuppressive agent $[54,55]$. A recent retrospective analysis of 172 patients with ANCA vasculitis treated with scheduled rituximab dosing every 4 months demonstrated achievement of continuous B-cell depletion and long-term disease control [56]. Controlled trials testing the effectiveness of rituximab as maintenance therapy are under way. Initial results from a prospective, randomized, controlled trial (MAINRITSAN) of patients with newly diagnosed $(n=91)$ or relapsing $(n=23)$ AAV who had achieved remission with standard therapy showed that rates of major relapse during maintenance therapy were lower among patients who received rituximab $500 \mathrm{mg}$ every 6 months than among those receiving azathioprine (5.2 versus $25.4 \%$ ) [57]. Another EUVAS randomized controlled trial (RITAZAREM) will investigate maintenance therapy with rituximab in patients with relapsing GPA/ MPA. Patients in remission at 4 months following rituximab $\left(4 \times 375 \mathrm{mg} / \mathrm{m}^{2}\right)$ will receive maintenance therapy with fixed-interval, repeat dosing with rituximab $(1,000 \mathrm{mg}$ every 4 months for 5 doses) or azathioprine [58]. Patients will be followed after cessation of therapy to test the hypothesis that repeat-dose rituximab during remission induces lasting remission through depletion of auto-reactive memory B cells.

An emerging observation with repeated rituximab exposure has been the development of hypogammaglobulinemia, which may increase in frequency in patients who have previously been exposed to cyclophosphamide before rituximab treatment [59]. In RAVE, a substantial proportion of GPA/MPA patients had low immunoglobulin levels at baseline, and low immunoglobulin levels were not associated with an increased risk of infection [60]. Similarly, a single-center study reported that $21 \%$ of patients had IgG levels below the lower limit of normal before rituximab treatment, with a trend toward lower levels after rituximab treatment over 2 years [52]. As reported for the RAVE cohort, there was no clear association between hypogammaglobulinemia and infections.

For patients who have previously relapsed on maintenance therapies, such as azathioprine or MMF, continuing these agents after rituximab appears to have little benefit [44]. Whether they reduce the risk of relapse after rituximab in treatment-naïve patients is not known.

In summary, available data indicate that once remission has been achieved, rituximab therapy using a fixed-interval re-treatment schedule is a potential alternative to azathioprine for remission-maintenance. The clinical importance of hypogammaglobulinemia with scheduled repeat doses of rituximab will be prospectively studied in ongoing and planned maintenance trials.

Rituximab in managing GPA/MPA patients with severe renal disease

\section{Concomitant use of cyclophosphamide}

The time to remission (defined as absence of clinical disease activity and a BVAS score of zero) after a rituximab course has been around 2 months whether or not concomitant therapy with cyclophosphamide was used. The RITUXVAS trial enrolled older patients with more severe renal disease, with a median e-GFR of $20 \mathrm{ml} / \mathrm{min}$, and included dialysis-dependent patients. Rituximab-treated patients received two doses of IV cyclophosphamide $15 \mathrm{mg} / \mathrm{kg}$ with the first course of rituximab [12]. Remission occurred in $91 \%$ of patients treated with rituximab, and at 12 months $76 \%$ had sustained remission and a median e-GFR of $39 \mathrm{ml} / \mathrm{min}$. However, in this older group with worse renal function at baseline, the mortality was $18 \%$ in each group. A single-center prospective study of 23 ANCA-associated renal vasculitis patients with a median e-GFR of $24 \mathrm{ml} / \mathrm{min}$ also used a lower dose of cyclophosphamide $(10 \mathrm{mg} / \mathrm{kg}$ ) with the initial course of rituximab [48]. Twenty-two of the 23 patients achieved remission and the median e-GFR was $42 \mathrm{ml} / \mathrm{min}$ by 6 months.

\section{Plasma exchange}

Plasma exchange is recommended as an adjunct to remission-induction therapy for selected patients with rapidly 
progressive severe renal disease in order to improve renal survival [25]. It is also recommended for certain patients with severe pulmonary disease and pulmonary hemorrhage. An open-label, randomized, controlled study is under way (PEXIVAS; NCT01697267), which aims to clearly determine both the role of plasma exchange in severe AAV and whether glucocorticoid dosing can be safely reduced. PEXIVAS will randomize patients with severe AAV to one of four study groups: plasma exchange + standard-dose glucocorticoids; plasma exchange + reduced-dose glucocorticoids; no plasma exchange + standard-dose glucocorticoids; or no plasma exchange + reduced-dose glucocorticoids. Although induction therapy will in most cases involve standard cyclophosphamide/high-dose glucocorticoids, rituximab is a permitted alternative for suitable patients. In such cases, rituximab should be dosed after the plasma exchange because of the potential for rituximab to be removed by plasma exchange.

Unique populations

\section{Transplantation}

In patients with ESRD, kidney transplantation improves survival compared with maintenance dialysis. Patients with renal AAV who receive transplantation appear to have reduced rates of vasculitis relapse compared with those who remain on dialysis [61]. However, relapse remains a significant clinical issue in transplant patients and selection of the optimal treatment for maintaining remission is clearly critical. Reintroduction of a cyclophosphamide/ high-dose glucocorticoid regimen has shown some success, albeit in a limited number of patients [62]. The use of rituximab in GPA/MPA patients post-transplantation has not been evaluated extensively, although a number of case reports suggest that rituximab is an effective alternative to standard induction therapy in this situation [63, 64].

\section{Pregnancy}

There is no evidence of a teratogenic risk with rituximab. However, given the lack of adequate data on safety on fetal exposure, rituximab is categorized as Category $\mathrm{C}$ drug, and effective contraception prior to the first infusion is recommended. In an assessment of the global safety database for rituximab in women who became pregnant, some complications and neonatal abnormalities were reported [65]. However, these may have been confounded by concomitant use of potentially teratogenic medications and severe underlying disease. Use of rituximab later in pregnancy is associated with B-cell depletion and low IgM levels in the newborn [66]. In a recent report of 157 women with vasculitis including 22 under the age of 40,6 patients undergoing treatment with rituximab became pregnant [56]. There were eight pregnancies in total. One miscarriage occurred at 15 weeks, and the rest of the pregnancies were uneventful. Maternal B cells were depleted at the time of delivery, while B-cell levels were normal in the fetal cord blood. In an individual case, the potential risks of rituximab in pregnancy must be balanced against the benefits of improved disease control and avoidance of other potentially toxic agents. Rituximab is classified by the FDA as a Category $\mathrm{C}$ drug with respect to pregnancy.

\section{Rituximab dosing}

The initial experience with rituximab in severe and refractory GPA/MPA used a regimen of $375 \mathrm{mg} / \mathrm{m}^{2}$ once weekly for 4 weeks $\left(4 \times 375 \mathrm{mg} / \mathrm{m}^{2}\right)$, and this dose and schedule was selected for the prospective RAVE and RITUXVAS trials and is the approved dose in the FDA label. This regimen has been used in most published studies to date, and results in a higher total dose than the standard regimen used in RA (two 1,000-mg infusions separated by 2 weeks). There have not been any dose-ranging studies in vasculitis to determine the optimal protocol, although one retrospective series of 65 patients reported that the $4 \times 375 \mathrm{mg} / \mathrm{m}^{2}$ and $2 \times 1,000-\mathrm{mg}$ regimens induced similar rates of remission (81 and $75 \%$, respectively) [44]. Another recent single- center experience with a protocolized treatment of ANCA vasculitis with a single dose of rituximab $375 \mathrm{mg} / \mathrm{m}^{2}$ demonstrated that the duration of B-cell depletion was similar to those reported in observational studies and an excellent clinical response with a 3-month probability of complete remission of $80 \%$ and significant cost savings [67].

\section{Rituximab side effects}

As of 2013 more than 220,000 patients have received rituximab for the treatment of RA (Roche/Genentech, data on file). Long-term follow-up data for patients treated with rituximab in RA indicate that it also has a good safety profile [68]. Nonetheless, rituximab use is associated with specific side effects, some of which can be fatal (these are fully reviewed in the product label [69]). Infusion-related reactions, most commonly on the initial infusion, can occur, and symptoms of serum-like sickness can develop later. Rituximab is a potent immunosuppressive agent and, as such, increases the risk of infections. However, rates of serious infections in rituximab-treated RA patients were similar to those reported in the general RA population, and there was no increased risk for opportunistic infections [68]. In the RAVE trial, $10 \%$ of patients suffered serious infections (sepsis or pneumonia). Although there have been reports of use of rituximab for remission-induction in the 
setting of severe infection, this use is not recommended, and the risks and benefits of such therapy must be weighed carefully [70]. Late-onset neutropenia has been observed with rituximab, but without increasing the risk of serious infections [56, 71]. Hypogammaglobulinemia is common during treatment with rituximab [60]; however, it remains to be fully determined if rituximab-induced hypogammaglobulinemia is associated with an increased risk of infection. Progressive multifocal leukoencephalopathy (PML) has occurred in association with rituximab in other indications [72], although it is very rare [ $<1$ case in 10,000 patient exposures in RA patients treated with rituximab (Roche/Genentech, data on file)]. Four cases of PML have been reported in patients with GPA in the absence of exposure to rituximab [72]. As of January 2013, there has been one confirmed case of PML in a 70-year-old breast cancer patient with GPA treated with rituximab and cyclophosphamide (Roche/Genentech, data on file). Rituximab has been reported to reactivate hepatitis B infections at times with severe consequences, and testing patients for HBsAg and anti $\mathrm{HB}$ core antibody is recommended. Although data in RA cannot be generalized to GPA/MPA, the long-term experience in rheumatology suggests that rituximab is not associated with an increased malignancy risk.

When is rituximab the first line of therapy in ANCA-associated vasculitis?

Based on available data, rituximab is the first line of therapy for induction of remission in patients who have severe AAV refractory to use of cyclophosphamide. Rituximab is preferred for induction of remission in severe AAV in young patients who wish to preserve fertility. Rituximab is superior to cyclophosphamide in patients with relapsing disease, especially those who are PR3 ANCA positive. However, the utility of rituximab alone in severely ill patients, such as those with renal involvement requiring dialysis at presentation and alveolar hemorrhage requiring mechanical ventilation, needs further study.

\section{Conclusions}

The combination of cyclophosphamide and high-dose glucocorticoids has remained the standard of care approach for remission-induction for the majority of patients with GPA or MPA over four decades. The high rate of remission achieved using this regimen means that it will remain an important therapeutic option. However, some patients fail to achieve remission with cyclophosphamide/glucocorticoid therapy, others suffer relapses during treatment, and there are well-recognized long-term toxicities associated with this regimen. Cyclophosphamide is not FDA approved for the treatment of ANCA-associated vasculitis. The availability of rituximab, which is FDA approved for this indication, now offers an alternative treatment option for the induction of remission in severe GPA/MPA. Rituximab may be considered a first choice therapy for patients with relapsing disease based on the RAVE data, and may be the preferred therapy for remission-induction for some young patients who wish to preserve fertility. The unanswered issues in the role of rituximab as an induction immunosuppressive agent include the use of concomitant cyclophosphamide and adjuvant plasma exchange for patients with life-threatening disease manifestations, and approaches to limit glucocorticoid exposure given the high incidence of AEs. The ongoing MAINRITSAN and RITAZAREM studies should provide a clearer picture of rituximab's safety and efficacy as maintenance therapy in the management of GPA/MPA.

Acknowledgments Support for third-party writing assistance for this manuscript was provided by F Hoffmann-La Roche Ltd.

Conflict of interest DG has served as a consultant for Genentech and has received honoraria from Genentech for teaching sales force. CK has received grant funding from Genentech for a clinical trial and speaker's fees from Roche. JHS has received grant funding from Genentech for a clinical trial, is the Global Principal Investigator in a multicenter clinical trial sponsored by Roche, and has performed consulting work for Genentech and Roche. GA has received speaker's honoraria and research grants for academic studies from Genentech and has served as a consultant for Genentech. DJ has received research grants for academic studies from Roche/Genentech. GD and PB are employees of Genentech. ADS declares no conflicts of interest.

\section{References}

1. Finkielman JD, Lee AS, Hummel AM, Viss MA, Jacob GL, Homburger HA, Peikert T, Hoffman GS, Merkel PA, Spiera R, St Clair EW, Davis JC, McCune WJ, Tibbs AK, Ytterberg SR, Stone JH, Specks U (2007) ANCA are detectable in nearly all patients with active severe Wegener's granulomatosis. Am J Med 120:643.e9-643.e14

2. Guillevin L, Durand-Gasselin B, Cevallos R, Gayraud M, Lhote F, Callard P, Amouroux J, Casassus P, Jarrousse B (1999) Microscopic polyangiitis: clinical and laboratory findings in eighty-five patients. Arthritis Rheum 42:421-430

3. Ntatsaki E, Watts RA, Scott DG (2010) Epidemiology of ANCAassociated vasculitis. Rheum Dis Clin North Am 36:447-461

4. Harris AA, Falk RJ, Jennette JC (1998) Crescentic glomerulonephritis with a paucity of glomerular immunoglobulin localization. Am J Kidney Dis 32:179-184

5. Jayne DR, Marshall PD, Jones SJ, Lockwood CM (1990) Autoantibodies to GBM and neutrophil cytoplasm in rapidly progressive glomerulonephritis. Kidney Int 37:965-970

6. Fauci AS, Haynes BF, Katz P, Wolff SM (1983) Wegener's granulomatosis: prospective clinical and therapeutic experience with 85 patients for 21 years. Ann Intern Med 98:76-85

7. Nachman PH, Hogan SL, Jennette JC, Falk RJ (1996) Treatment response and relapse in antineutrophil cytoplasmic autoantibody- 
associated microscopic polyangiitis and glomerulonephritis. J Am Soc Nephrol 7:33-39

8. Hoffman GS, Kerr GS, Leavitt RY, Hallahan CW, Lebovics RS, Travis WD, Rottem M, Fauci AS (1992) Wegener granulomatosis: an analysis of 158 patients. Ann Intern Med 116:488-498

9. Little MA, Nightingale P, Verburgh CA, Hauser T, De Groot K, Savage C, Jayne D, Harper L (2010) Early mortality in systemic vasculitis: relative contribution of adverse events and active vasculitis. Ann Rheum Dis 69:1036-1043

10. Jennette JC, Xiao H, Falk RJ (2006) Pathogenesis of vascular inflammation by anti-neutrophil cytoplasmic antibodies. J Am Soc Nephrol 17:1235-1242

11. Stone JH, Merkel PA, Spiera R, Seo P, Langford CA, Hoffman GS, Kallenberg CG, St Clair EW, Turkiewicz A, Tchao NK, Webber L, Ding L, Sejismundo LP, Mieras K, Weitzenkamp D, Ikle D, Seyfert-Margolis V, Mueller M, Brunetta P, Allen NB, Fervenza FC, Geetha D, Keogh KA, Kissin EY, Monach PA, Peikert T, Stegeman C, Ytterberg SR, Specks U (2010) Rituximab versus cyclophosphamide for ANCA-associated vasculitis. N Engl J Med 363:221-232

12. Jones RB, Tervaert JW, Hauser T, Luqmani R, Morgan MD, Peh CA, Savage CO, Segelmark M, Tesar V, van Paassen P, Walsh D, Walsh M, Westman K, Jayne DR (2010) Rituximab versus cyclophosphamide in ANCA-associated renal vasculitis. N Engl J Med 363:211-220

13. Mukhtyar C, Guillevin L, Cid MC, Dasgupta B, de Groot K, Gross W, Hauser T, Hellmich B, Jayne D, Kallenberg CG, Merkel PA, Raspe H, Salvarani C, Scott DG, Stegeman C, Watts R, Westman K, Witter J, Yazici H, Luqmani R (2009) EULAR recommendations for the management of primary small and medium vessel vasculitis. Ann Rheum Dis 68:310-317

14. de Groot K, Harper L, Jayne DR, Flores-Suarez LF, Gregorini G, Gross WL, Luqmani R, Pusey CD, Rasmussen N, Sinico RA, Tesar V, Vanhille P, Westman K, Savage CO (2009) Pulse versus daily oral cyclophosphamide for induction of remission in antineutrophil cytoplasmic antibody-associated vasculitis: a randomized trial. Ann Intern Med 150:670-680

15. Guillevin L, Cordier JF, Lhote F, Cohen P, Jarrousse B, Royer I, Lesavre P, Jacquot C, Bindi P, Bielefeld P, Desson JF, Detree F, Dubois A, Hachulla E, Hoen B, Jacomy D, Seigneuric C, Lauque D, Stern M, Longy-Boursier M (1997) A prospective, multicenter, randomized trial comparing steroids and pulse cyclophosphamide versus steroids and oral cyclophosphamide in the treatment of generalized Wegener's granulomatosis. Arthritis Rheum 40:2187-2198

16. Harper L, Morgan MD, Walsh M, Hoglund P, Westman K, Flossmann O, Tesar V, Vanhille P, de Groot K, Luqmani R, Flores-Suarez LF, Watts R, Pusey C, Bruchfeld A, Rasmussen N, Blockmans D, Savage CO, Jayne D (2012) Pulse versus daily oral cyclophosphamide for induction of remission in ANCA-associated vasculitis: long-term follow-up. Ann Rheum Dis 71:955-960

17. Jayne D, Rasmussen N, Andrassy K, Bacon P, Tervaert JW, Dadoniene J, Ekstrand A, Gaskin G, Gregorini G, de Groot K, Gross W, Hagen EC, Mirapeix E, Pettersson E, Siegert C, Sinico A, Tesar V, Westman K, Pusey C (2003) A randomized trial of maintenance therapy for vasculitis associated with antineutrophil cytoplasmic autoantibodies. N Engl J Med 349:36-44

18. Walsh M, Merkel PA, Mahr A, Jayne D (2010) Effects of duration of glucocorticoid therapy on relapse rate in antineutrophil cytoplasmic antibody-associated vasculitis: a meta-analysis. Arthritis Care Res (Hoboken) 62:1166-1173

19. Hiemstra TF, Walsh M, Mahr A, Savage CO, de Groot K, Harper L, Hauser T, Neumann I, Tesar V, Wissing KM, Pagnoux C, Schmitt W, Jayne DR (2010) Mycophenolate mofetil vs azathioprine for remission maintenance in antineutrophil cytoplasmic antibody-associated vasculitis: a randomized controlled trial. JAMA 304:2381-2388

20. Pagnoux C, Mahr A, Hamidou MA, Boffa JJ, Ruivard M, Ducroix JP, Kyndt X, Lifermann F, Papo T, Lambert M, Le Noach J, Khellaf M, Merrien D, Puechal X, Vinzio S, Cohen P, Mouthon L, Cordier JF, Guillevin L (2008) Azathioprine or methotrexate maintenance for ANCA-associated vasculitis. N Engl J Med 359:2790-2803

21. De Groot K, Rasmussen N, Bacon PA, Tervaert JW, Feighery C, Gregorini G, Gross WL, Luqmani R, Jayne DR (2005) Randomized trial of cyclophosphamide versus methotrexate for induction of remission in early systemic antineutrophil cytoplasmic antibody-associated vasculitis. Arthritis Rheum 52:2461-2469

22. Faurschou M, Westman K, Rasmussen N, de Groot K, Flossmann O, Höglund P, Jayne DR, European Vasculitis Study Group (2012) Brief report: long-term outcome of a randomized clinical trial comparing methotrexate to cyclophosphamide for remission induction in early systemic antineutrophil cytoplasmic antibodyassociated vasculitis. Arthritis Rheum 64:3472-3477

23. Silva F, Specks U, Kalra S, Hogan MC, Leung N, Sethi S, Fervenza FC (2010) Mycophenolate mofetil for induction and maintenance of remission in microscopic polyangiitis with mild to moderate renal involvement-a prospective, open-label pilot trial. Clin J Am Soc Nephrol 5:445-453

24. Jones RB, Walsh M (2012) A randomised trial of mycophenolate mofetil versus cyclophosphamide for remission induction in ANCA-associated vasculitis: MYCYC. J Am Soc Nephrol 23:3B

25. Jayne DR, Gaskin G, Rasmussen N, Abramowicz D, Ferrario F, Guillevin L, Mirapeix E, Savage CO, Sinico RA, Stegeman CA, Westman KW, van der Woude FJ, de Lind van Wijngaarden RA, Pusey CD (2007) Randomized trial of plasma exchange or highdosage methylprednisolone as adjunctive therapy for severe renal vasculitis. J Am Soc Nephrol 18:2180-2188

26. Rovin BH, Furie R, Latinis K, Looney RJ, Fervenza FC, Sanchez-Guerrero J, Maciuca R, Zhang D, Garg JP, Brunetta P, Appel G, LUNAR Investigator Group (2012) Efficacy and safety of rituximab in patients with active proliferative lupus nephritis: the Lupus Nephritis Assessment with Rituximab study. Arthritis Rheum 64:1215-1226

27. Magnasco A, Ravani P, Edefonti A, Murer L, Ghio L, Belingheri M, Benetti E, Murtas C, Messina G, Massella L, Porcellini MG, Montagna M, Regazzi M, Scolari F, Ghiggeri GM (2012) Rituximab in children with resistant idiopathic nephrotic syndrome. J Am Soc Nephrol 23:1117-1124

28. Ruggenenti P, Cravedi P, Chianca A, Perna A, Ruggiero B, Gaspari F, Rambaldi A, Marasà M, Remuzzi G (2012) Rituximab in idiopathic membranous nephropathy. J Am Soc Nephrol 23:1416-1425

29. Fervenza FC, Abraham RS, Erickson SB, Irazabal MV, Eirin A, Specks U, Nachman PH, Bergstralh EJ, Leung N, Cosio FG, Hogan MC, Dillon JJ, Hickson LJ, Li X, Cattran DC, Mayo Nephrology Collaborative Group (2010) Rituximab therapy in idiopathic membranous nephropathy: a 2-year study. Clin J Am Soc Nephrol 5:2188-2198

30. Gomez-Puerta JA, Quintana LF, Stone JH, Ramos-Casals M, Bosch X (2012) B-cell depleting agents for ANCA vasculitides: a new therapeutic approach. Autoimmun Rev 11:646-652

31. Cupps TR, Edgar LC, Fauci AS (1982) Suppression of human B lymphocyte function by cyclophosphamide. J Immunol 128:2453-2457

32. Keogh KA, Wylam ME, Stone JH, Specks U (2005) Induction of remission by $\mathrm{B}$ lymphocyte depletion in eleven patients with refractory antineutrophil cytoplasmic antibody-associated vasculitis. Arthritis Rheum 52:262-268 
33. Stasi R, Stipa E, Del Poeta G, Amadori S, Newland AC, Provan D (2006) Long-term observation of patients with anti-neutrophil cytoplasmic antibody-associated vasculitis treated with rituximab. Rheumatology (Oxford) 45:1432-1436

34. Eriksson P (2005) Nine patients with anti-neutrophil cytoplasmic antibody-positive vasculitis successfully treated with rituximab. J Intern Med 257:540-548

35. Stone JH, Hoffman GS, Merkel PA, Min YI, Uhlfelder ML, Hellmann DB, Specks U, Allen NB, Davis JC, Spiera RF, Calabrese LH, Wigley FM, Maiden N, Valente RM, Niles JL, Fye $\mathrm{KH}$, McCune JW, St Clair EW, Luqmani RA, International Network for the Study of the Systemic Vasculitides (INSSYS) (2001) A disease-specific activity index for Wegener's granulomatosis: modification of the Birmingham Vasculitis Activity Score. International Network for the Study of the Systemic Vasculitides (INSSYS). Arthritis Rheum 44:912-920

36. Specks U, Merkel PA, Seo P, Spiera R, Langford CA, Hoffman GS, Kallenberg CG, St Clair EW, Fessler BJ, Ding L, Viviano L, Tchao NK, Phippard DJ, Asare AL, Lim N, Ikle D, Jepson B, Brunetta P, Allen NB, Fervenza FC, Geetha D, Keogh K, Kissin EY, Monach PA, Peikert T, Stegeman C, Ytterberg SR, Mueller M, Sejismundo LP, Mieras K, Stone JH (2013) Efficacy of remission-induction regimens for ANCA-associated vasculitis. N Engl J Med 369:417-427

37. Geetha D, Fervenza FC, RAVE-ITN Group (2012) The efficacy of rituximab versus cyclophosphamide for treatment of renal disease in ANCA-associated vasculitis: the RAVE trial. J Am Soc Nephrol 23:88A

38. Stone J, Merkel P, Seo P et al (2011) Extended follow-up of treatment with rituximab versus cyclophosphamide for remission induction of AAV: which disease subsets are at greatest risk for disease flare? Arthritis Rheum 63(Suppl):S946

39. Rutgers A, Kallenberg CG (2012) Refractory disease in antineutrophil cytoplasmic antibodies associated vasculitis. Curr Opin Rheumatol 24:245-251

40. Specks U, Fervenza FC, McDonald TJ, Hogan MC (2001) Response of Wegener's granulomatosis to anti-CD20 chimeric monoclonal antibody therapy. Arthritis Rheum 44:2836-2840

41. Keogh KA, Ytterberg SR, Fervenza FC, Carlson KA, Schroeder DR, Specks U (2006) Rituximab for refractory Wegener's granulomatosis: report of a prospective, open-label pilot trial. Am J Respir Crit Care Med 173:180-187

42. Smith KG, Jones RB, Burns SM, Jayne DR (2006) Long-term comparison of rituximab treatment for refractory systemic lupus erythematosus and vasculitis: remission, relapse, and re-treatment. Arthritis Rheum 54:2970-2982

43. Pullerits R, Ljevak M, Vikgren J, Bokarewa M (2012) Off-trial evaluation of the B cell-targeting treatment in the refractory cases of antineutrophil cytoplasmic antibodies (ANCA)-associated vasculitis: long-term follow-up from a single centre. Scand J Immunol 76:411-420

44. Jones RB, Ferraro AJ, Chaudhry AN, Brogan P, Salama AD, Smith KG, Savage CO, Jayne DR (2009) A multicenter survey of rituximab therapy for refractory antineutrophil cytoplasmic antibody-associated vasculitis. Arthritis Rheum 60:2156-2168

45. Rota S, Rambaldi A, Gaspari F, Noris M, Daina E, Benigni A, Perna A, Donadelli R, Remuzzi G, Garattini S (1992) Methylprednisolone dosage effects on peripheral lymphocyte subpopulations and eicosanoid synthesis. Kidney Int 42:981-990

46. Wolfe F, Caplan L, Michaud K (2006) Treatment for rheumatoid arthritis and the risk of hospitalization for pneumonia: associations with prednisone, disease-modifying antirheumatic drugs, and anti-tumor necrosis factor therapy. Arthritis Rheum 54:628-634

47. Saag KG, Koehnke R, Caldwell JR, Brasington R, Burmeister LF, Zimmerman B, Kohler JA, Furst DE (1994) Low dose long-term corticosteroid therapy in rheumatoid arthritis: an analysis of serious adverse events. Am J Med 96:115-123

48. Mansfield N, Hamour S, Habib AM, Tarzi R, Levy J, Griffith M, Cairns T, Cook HT, Pusey CD, Salama AD (2011) Prolonged disease-free remission following rituximab and low-dose cyclophosphamide therapy for renal ANCA-associated vasculitis. Nephrol Dial Transplant 26:3280-3286

49. McGregor JG, Hogan SL, Hu Y, Jennette CE, Falk RJ, Nachman PH (2012) Glucocorticoids and relapse and infection rates in antineutrophil cytoplasmic antibody disease. Clin J Am Soc Nephrol 7:240-247

50. Hogan SL, Falk RJ, Chin H, Cai J, Jennette CE, Jennette JC, Nachman PH (2005) Predictors of relapse and treatment resistance in antineutrophil cytoplasmic antibody-associated smallvessel vasculitis. Ann Intern Med 143:621-631

51. Franssen CF, Stegeman CA, Kallenberg CG, Gans RO, De Jong PE, Hoorntje SJ, Tervaert JW (2000) Antiproteinase 3- and antimyeloperoxidase-associated vasculitis. Kidney Int 57:2195-2206

52. Smith RM, Jones RB, Guerry MJ, Laurino S, Catapano F, Chaudhry A, Smith KG, Jayne DR (2012) Rituximab for remission maintenance in relapsing antineutrophil cytoplasmic antibody-associated vasculitis. Arthritis Rheum 64:3760-3769

53. Cartin-Ceba R, Golbin JM, Keogh KA, Peikert T, Sanchez-Menendez M, Ytterberg SR, Fervenza FC, Specks U (2012) Rituximab for remission induction and maintenance in refractory granulomatosis with polyangiitis (Wegener's): ten-year experience at a single center. Arthritis Rheum 64:3770-3778

54. Rhee EP, Laliberte KA, Niles JL (2010) Rituximab as maintenance therapy for anti-neutrophil cytoplasmic antibody-associated vasculitis. Clin J Am Soc Nephrol 5:1394-1400

55. Roubaud-Baudron C, Pagnoux C, Meaux-Ruault N, Grasland A, Zoulim A, Le Guen J, Prud'homme A, Bienvenu B, de Menthon M, Camps S, Le Guern V, Aouba A, Cohen P, Mouthon L, Guillevin L (2012) Rituximab maintenance therapy for granulomatosis with polyangiitis and microscopic polyangiitis. J Rheumatol 39: $125-130$

56. Pendergraft WF 3rd, Cortazar FC, Wenger J, Murphy AP, Rhee EP, Laliberte KA, Niles JL (2014) Long-term maintenance therapy using rituximab-induced continuous B-cell depletion in patients with ANCA vasculitis. Clin J Am Soc Nephrol 9:736-744

57. Guillevin L, Pagnoux C, Karras A, Khoutra C, Aumaitre O, Cohen P, Maurier F, Decaux O, Desmurs-Clavel H, Gobert P, Quemeneur T, Blanchard-Delaunay C, Godmer P, Puechal X, Carron PL, Yves Hatron P, Limal N, Hamidou M, Ducret M, Vende F, Pasqualoni E, Bonnotte B, Ravaud P, Mouthon L Sr, French Vasculitis Study Group (FVSG) (2012) Rituximab versus azathioprine for maintenance in antineutrophil cytoplasmic antibodies (ANCA)-associated vasculitis. Arthritis Rheum 64 (Suppl):S706

58. Jayne DR, Smith RM, Merkel PA (2012) RITAZAREM: an international, open label, randomized, controlled trial comparing rituximab with azathioprine as maintenance therapy in relapsing ANCA-associated vasculitis. J Am Soc Nephrol 23:707A

59. Venhoff N, Effelsberg NM, Salzer U, Warnatz K, Peter HH, Lebrecht D, Schlesier M, Voll RE, Thiel J (2012) Impact of rituximab on immunoglobulin concentrations and $\mathrm{B}$ cell numbers after cyclophosphamide treatment in patients with ANCA-associated vasculitides. PLoS ONE 7:e37626

60. Specks U, Merkel PA, Seo P et al (2011) Immunoglobulin concentrations and infection risk among patients with ANCA-associated vasculitis treated with rituximab or cyclophosphamide. Arthritis Rheum 63:S310

61. Geetha D, Eirin A, True K, Valentina Irazabal M, Specks U, Seo P, Nachman P, Fervenza FC (2007) Renal transplantation in 
antineutrophil cytoplasmic antibody-associated vasculitis: a multicenter experience. Transplantation 91:1370-1375

62. Nachman PH, Segelmark M, Westman K, Hogan SL, Satterly KK, Jennette JC, Falk R (1999) Recurrent ANCA-associated small vessel vasculitis after transplantation: a pooled analysis. Kidney Int 56:1544-1550

63. Murakami C, Manoharan P, Carter-Monroe N, Geetha D (2013) Rituximab for remission induction in recurrent ANCA-associated glomerulonephritis postkidney transplant. Transplant Int 26:1225-1231

64. Geetha D, Seo P, Specks U, Fervenza FC (2007) Successful induction of remission with rituximab for relapse of ANCAassociated vasculitis post-kidney transplant: report of two cases. Am J Transplant 7:2821-2825

65. Chakravarty EF, Murray ER, Kelman A, Farmer P (2011) Pregnancy outcomes after maternal exposure to rituximab. Blood 117:1499-1506

66. Klink DT, van Elburg RM, Schreurs MW, van Well GT (2008) Rituximab administration in third trimester of pregnancy suppresses neonatal B-cell development. Clin Dev Immunol 2008:271363

67. Turner-Stokes T, Sandhu E, Pepper RJ, Stolagiewicz NE, Ashley C, Dinneen D, Howie AJ, Salama AD, Burns A, Little MA (2014)
Induction treatment of ANCA-associated vasculitis with a single dose of rituximab. Rheumatology (Oxford) (Epub ahead of print)

68. van Vollenhoven RF, Emery P, Bingham CO 3rd, Keystone EC, Fleischmann RM, Furst DE, Tyson N, Collinson N, Lehane PB (2013) Long-term safety of rituximab in rheumatoid arthritis: 9.5year follow-up of the global clinical trial programme with a focus on adverse events of interest in RA patients. Ann Rheum Dis 72:1496-1502

69. Rituxan (rituximab) [package insert] (2013) Genentech Inc, South San Francisco

70. Gregersen JW, Chaudhry A, Jayne DR (2013) Rituximab for ANCA-associated vasculitis in the setting of severe infection. Scand J Rheumatol 42:207-210

71. Besada E, Koldingsnes W, Nossent J (2012) Characteristics of late onset neutropenia in rheumatologic patients treated with rituximab: a case review analysis from a single center. QJM 105:545-550

72. Molloy ES, Calabrese LH (2012) Progressive multifocal leukoencephalopathy associated with immunosuppressive therapy in rheumatic diseases: evolving role of biologic therapies. Arthritis Rheum 64:3043-3051 